\title{
Birmingham Vasculitis Activity Score
}

National Cancer Institute

\section{Source}

National Cancer Institute. Birmingham Vasculitis Activity Score. NCI Thesaurus. Code C121343.

A set of criteria used to determine the activity of vasculitis. 